\title{
A novel role for the glutamate decarboxylase system in Listeria monocytogenes; protection against oxidative stress
}

\section{Article}

Accepted Version

Creative Commons: Attribution-Noncommercial-No Derivative Works 4.0

Boura, M., Brensone, D. and Karatzas, K.-A. G. (2020) A novel role for the glutamate decarboxylase system in Listeria monocytogenes; protection against oxidative stress. Food Microbiology, 85. 103284. ISSN 0740-0020 doi: https://doi.org/10.1016/j.fm.2019.103284 Available at https://centaur.reading.ac.uk/85402/

It is advisable to refer to the publisher's version if you intend to cite from the work. See Guidance on citing.

To link to this article DOI: http://dx.doi.org/10.1016/j.fm.2019.103284

Publisher: Elsevier

All outputs in CentAUR are protected by Intellectual Property Rights law, including copyright law. Copyright and IPR is retained by the creators or other copyright holders. Terms and conditions for use of this material are defined in the End User Agreement. 


\section{CentAUR}

Central Archive at the University of Reading

Reading's research outputs online 


\section{Journal Pre-proof}

A novel role for the glutamate decarboxylase system in Listeria monocytogenes; protection against oxidative stress

Marcia Boura, Dace Brensone, Kimon A.G. Karatzas

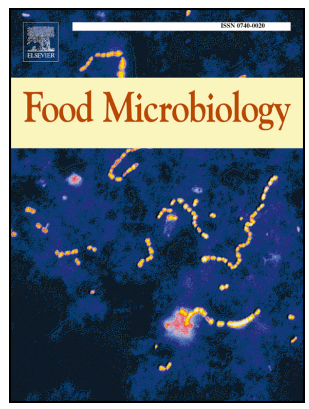

PII:

S0740-0020(19)30666-5

DOI:

https://doi.org/10.1016/j.fm.2019.103284

Reference: $\quad$ YFMIC 103284

To appear in: Food Microbiology

Received Date: 28 June 2019

Accepted Date: 30 July 2019

Please cite this article as: Boura, M., Brensone, D., Karatzas, K.A.G., A novel role for the glutamate decarboxylase system in Listeria monocytogenes; protection against oxidative stress, Food Microbiology (2019), doi: https://doi.org/10.1016/j.fm.2019.103284.

This is a PDF file of an article that has undergone enhancements after acceptance, such as the addition of a cover page and metadata, and formatting for readability, but it is not yet the definitive version of record. This version will undergo additional copyediting, typesetting and review before it is published in its final form, but we are providing this version to give early visibility of the article. Please note that, during the production process, errors may be discovered which could affect the content, and all legal disclaimers that apply to the journal pertain.

(C) 2019 Published by Elsevier Ltd. 


\section{Journal Pre-proof}

1 A novel role for the glutamate decarboxylase system in Listeria monocytogenes;

2 protection against oxidative stress

3 Marcia Boura ${ }^{1}$, Dace Brensone ${ }^{1}$, Kimon A.G. Karatzas ${ }^{1 *}$

4

5 1. Department of Food \& Nutritional Sciences, University of Reading, Reading, United

6 Kingdom

$7 *$ Authors for correspondence

8 Dr. Kimon Andreas G. Karatzas

9 Department of Food \& Nutritional Sciences

10 University of Reading,

11 Whiteknights, PO Box 226

12 Reading RG6 6AD UK

13 Room 3-38

14 Tel. +44118378 6678 Fax. +44 1189310080

15 Email: k.karatzas@ reading.ac.uk

16

17

18

19

20

21

22

23

24

25

26

27

28

29

30

31 


\section{Abstract}

The GAD system is widely present in several types of organisms and is known to play an important role in bacterial acid tolerance. There is only one account of this system playing a role in oxidative stress in bacteria and one in yeasts. Here we show for first time that it affects the oxidative stress resistance of a Gram-positive bacterium, (L. monocytogenes, tested in three strains; 10403S, EGD-e, and LO28). We found a statistically significant reduction in survival after $\mathrm{H}_{2} \mathrm{O}_{2}$ exposure in $\triangle g a d D 3$ and $\Delta g a d D 2$ of EGD-e and in $\Delta g a d D 1$ of LO28. Furthermore, we observed a lag phase prolongation in $\triangle g a d D 3$ of $10403 \mathrm{~S}$ and EGD-e and a larger inhibition zone in disk diffusion assay for $\Delta g a d D 1$ and $\Delta g a d D 3$ of EGD-e upon $\mathrm{H}_{2} \mathrm{O}_{2}$ exposure. All GAD genes playing a role in oxidative stress resistance are part of $\mathrm{GAD}_{\mathrm{i}}$ system while this occurs partly through catalase activity, while the most potent $\mathrm{GAD}_{\mathrm{e}}$ system plays no role. The latter effects could occur through the GABA shunt, but we show here that mutants in succinate semialdehyde dehydrogenase do not show a phenotype suggesting that either effects are through the GABA transaminase or, this pathway is not involved. Our study highlights for first time the role of the GAD system in oxidative stress resistance of a Gram-positive bacterium, which could be used in Food Hurdle Technology to eliminate pathogens such as L. monocytogenes, while it gives an insight on the general mechanism. 


\section{Introduction}

Listeria monocytogenes is the causative agent of listeriosis, a life-threatening food borne disease, with a mortality rate reaching the $30 \%$ in some outbreaks (Allerberger and Wagner, 2010; Mead et al., 1999). Its success is often attributed to the ability to survive in a large range of adverse conditions, including acidic environments (Cole et al., 1990; Mcclure et al., 1989). Such feature is especially important for foodborne pathogens, in order to withstand the acidic $\mathrm{pH}$ encountered both during food disinfection and during the infectious process, in the human stomach (Feehily and Karatzas, 2013). In order to cope with acid challenge, bacteria employ a variety of strategies. One of best characterized acid resistance mechanisms is the glutamate decarboxylase (GAD) system (Cotter et al., 2001; Feehily and Karatzas, 2013), which is present in all kingdoms of life (Paudyal and Karatzas, 2016), and presents a wide variety of functions in different organisms (Feehily and Karatzas, 2013). Although the system is a major part of the nervous system of animals, and a defence mechanism to stress such as anoxic conditions in plants, in a wide variety of microorganisms including fungi and bacteria such as $L$. monocytogenes, Escherichia coli, Francisella tularensis, it is a major acid resistance mechanism (Karatzas et al., 2012; Ramond et al., 2014; Smith et al., 1992). Despite the architecture of the system showing variability in different species, generally, in L. monocytogenes, the system comprises three glutamate decarboxylase enzymes (GadD1, GadD2 and GadD3), and two glutamate/GABA antiporters (GadT1 and T2; Paul D. Cotter et al., 2005; Karatzas et al., 2012). There is, however, a high variability in the architecture of the GAD system, even between different strains of the same species. For instance, L. monocytogenes stains belonging to serotype 4 , which is the serotype more often associated with foodborne outbreaks, lack the gadDIT1 operon (P. D. Cotter et al., 2005). The system works in a cycle that initiates with the import of extracellular glutamate $\left(\mathrm{Glt}_{\mathrm{e}}\right)$ by the antiporters, which is decarboxylated by the decarboxylase enzymes through replacement of the $\alpha$-carboxyl group with a proton, resulting in $\gamma$-aminobutyric acid (GABA) formation. The GABA produced is subsequently exported back by the antiporter, while simultaneously more glutamate is imported, hence continuing the cycle (O'Byrne and Karatzas, 2008). The consumption of one proton during glutamate 
87 decarboxylation is responsible for an increase of the intracellular $\mathrm{pH}$, attenuating the acid stress (Cotter et al., 2001). Furthermore, the GAD enzymes can utilize intracellular glutamate $\left(\mathrm{Glt}_{\mathrm{i}}\right)$ in order to increase the intracellular $\mathrm{pH}$ (Karatzas et al., 2012). In L. monocytogenes, a GAD enzyme, generally the GadD3, is not associated with any antiporter and it is believed to be responsible for processing $\mathrm{Glt}_{\mathrm{i}}$ (Karatzas et al., 2012). The GABA produced via the intracellular GAD system $\left(\mathrm{GAD}_{\mathrm{i}}\right)$ is catabolised to succinate via the GABA shunt pathway, which is a twostep enzymatic pathway catalysed by the enzymes GABA amino-transferase (GABA-AT) and succinate semialdheyde dehydrogenase (SSADH; Zhu et al., 2010). The contribution of $\mathrm{GAD}_{\mathrm{i}}$ in acid tolerance is dependent on the strain. In L. monocytogenes EGD-e the $\mathrm{GAD}_{\mathrm{i}}$ system plays crucial role for acid resistance, since this strain has a defective extracellular GAD $\left(\mathrm{GAD}_{\mathrm{e}}\right)$ system and is unable to export GABA (Karatzas et al., 2012).

In other organisms, the GAD system is known to play other roles aside from conferring acid resistance. For instance, in plants the production of GABA has been associated with several types of stress such as mechanical, draught, salt, heat and cold stresses (Kinnersley et al., 2000). Aside from stress-related functions, the GAD system is known to play an important role in the mammalian brain where GABA functions as the major inhibitory neuro-transmitter (Petroff, 2002). Interestingly, in several organisms, ranging from F. tularensis (Ramond et al., 2014) to Saccharomyces cerevisiae (Coleman et al., 2001) and astrocytes (Bellier et al., 2000; Lamigeon et al., 2001), the presence of a functional GAD system has been associated with an adequate response to oxidative stress. The exact mechanism is not well understood, however most studies suggest that a deficient GAD system leads to a reduction of intermediates of the tricarboxylic acid (TCA) cycle and other molecules, such as NADPH and glutathione, which have potent anti-oxidant capacity (Bellier et al., 2000; Coleman et al., 2001; Lamigeon et al., 2001; Ramos et al., 1985; Smirnova and Oktyabrsky, 2017; Vogel et al., 1999).

In $L$. monocytogenes, possibly due to the well-known role for acid resistance, to date, it has not been assessed if the GAD system mediates the response to other types of stress apart from resistance to nisin mediated by GadD1 in LO28 (Begley et al., 2010). This is important since the role of GadD1 in acid resistance is not clear. There is limited evidence involving GAD system 
115 and GABA metabolism in oxidative tolerance. This is especially relevant, since oxidative stress

116 is one of the most common stresses L. monocytogenes has to cope with. It occurs not only in the

117 environment, as a consequence of aerobiosis but also during the infectious process, inside the

118 phagolysosome, or during disinfection, as oxidants are often used, and in the processing of

119 foods with technologies such as plasma and ozone (Cabiscol et al., 2000; Imlay, 2003; Jaksch et

120 al., 2004; O'Byrne and Karatzas, 2008; O'Donnell et al., 2012). The utilization of oxidising

121 agents is highly appealing for the food industry since it reduces the microbial activity

122 significantly and without the inconvenient traces of toxic residues and by-products (Jaksch et

123 al., 2004; O’Donnell et al., 2012).

124 In the current study, we aimed to elucidate the role of different components of the GAD system in three L. monocytogenes strains (10403S, EGD-e and LO28) in oxidative stress tolerance. We show, for the first time in L. monocytogenes, a secondary role of protection against oxidative stress for the GAD system. This effect is only seen with components of the $\mathrm{GAD}_{\mathrm{i}}$ system, which lead us to hypothesise that the $\mathrm{GAD}_{\mathrm{i}}$ in $L$. monocytogenes contributes to the maintenance of intracellular antioxidant molecules key for bacterial tolerance to oxidative stress. Our study highlights for first time the important role of the GAD system in oxidative stress in a Grampositive bacterium. Our observations have great impact on the understanding of this phenomenon in all organisms from all kingdoms of life and most importantly in bacteria. More specifically in L. monocytogenes this phenomenon is important for the wider understanding of its complex behaviour when it encounters different types of stress. This work could be considered in Hurdle Technology and thus help us in the easier elimination of this pathogen from foods and food preparation environments.

2. Materials and Methods

\subsection{Bacterial strains and growth}

140 L. monocytogenes WT strains of EGD-e, $10403 \mathrm{~S}$ and LO28 and their isogenic mutants in 141 different genes of the GAD system (Table 1) were used in this study. Stock cultures were stored at $-80^{\circ} \mathrm{C}$ in $15 \%$ (v/v) dimethyl sulfoxide (DMSO) (Sigma-Aldrich, Dorset, United Kingdom). 
143 Prior to experiments, stock cultures were streaked onto brain heart infusion (BHI) agar (LAB M,

144 Lancashire, United Kingdom) and incubated at $37^{\circ} \mathrm{C}$ overnight.

145 A single colony was transferred to $3 \mathrm{ml}$ of either sterile BHI broth (LAB M) for EGD-e and $14610403 \mathrm{~S}$ or tryptone soy broth (Lab M) supplemented with $0.6 \%(\mathrm{w} / \mathrm{v})$ of yeast extract (TSBY) 147 for $\mathrm{LO} 28$ and incubated at $37^{\circ} \mathrm{C}$ with shaking (160 rpm). Bacteria were allowed to grow until stationary phase and used to inoculate the experimental culture with a $1 \%$ inoculum (v/v). These

149 cultures were prepared in $250 \mathrm{ml}$ conical flasks containing $20 \mathrm{ml}$ of the same medium as used 150 for the inoculum and incubated overnight at $37^{\circ} \mathrm{C}$ with shaking $(120 \mathrm{rpm})$.

\subsection{Growth in the presence of sub-lethal doses of $\mathrm{H}_{2} \mathrm{O}_{2}$}

L. monocytogenes was grown overnight in the appropriate broth containing a sub-lethal concentration of $\mathrm{H}_{2} \mathrm{O}_{2}(0.01 \%)$. The cultures were incubated at $37^{\circ} \mathrm{C}$ and the optical density at $620 \mathrm{~nm}$ was measured every 20 minutes in a Sunrise plate reader (Tecan, Austria). The Baranyi and Roberts model was used to estimate the growth parameters (length of lag phase, growth rate and maximum OD; Baranyi et al., 1996; Baranyi and Roberts, 1994), taking advantage of the embedded analysis tool of Microsoft Excel 2013, Solver, as previously described (Walsh and Diamond, 1995).

\subsection{Hydrogen Peroxide Disk Diffusion Assay}

Overnight liquid cultures grown either in BHI (EGD-e and 10403S) or TSBY (LO28) were diluted to an $\mathrm{OD}_{600 \mathrm{~nm}}$ of 0.2 , and $100 \mu \mathrm{l}$ was spread onto Mueller-Hinton agar (MHA; Oxoid, Basingstoke, United Kingdom). Then, $10 \mu \mathrm{l}$ of $30 \%$ (v/v) $\mathrm{H}_{2} \mathrm{O}_{2}$ was pipetted onto Whatman $3 \mathrm{MM}$ paper disks $(0.7-\mathrm{cm}$ diameter), and these disks were placed on top of the agar and incubated for $18 \mathrm{~h}$ at $37^{\circ} \mathrm{C}$. The zones of inhibition (in mm) denoting $\mathrm{H}_{2} \mathrm{O}_{2}$ sensitivity were measured in three dimensions, and the mean values and standard deviations were calculated. All experiments were performed on three independent biological replicates. 
2.4. Survival against $\mathrm{H}_{2} \mathrm{O}_{2}$

171 Stationary phase aerobic cultures, grown as described for $18 \mathrm{~h}$, were challenged with $4 \%$

172 (10403S and LO28) or $4.5 \%$ (EGD-e) of $\mathrm{H}_{2} \mathrm{O}_{2}$. The survival pattern was assessed by plating

173 serial dilutions in either BHI or TSBY agar before and after (20, 40 and $60 \mathrm{~min})$ the $\mathrm{H}_{2} \mathrm{O}_{2}$

174 challenge. The agar plates were incubated at $37^{\circ} \mathrm{C}$ for $24 \mathrm{~h}$ and colony forming units (CFU)

175 were enumerated to assess the concentration of bacteria in each time point.

\subsection{Catalase activity assay}

The catalase activity was assessed using the methodology described by Iwase et al. (2013), with minor modifications. Briefly, $10 \mathrm{mg}$ of bacterial culture pellet was re-suspended in $100 \mu \mathrm{l}$ phosphate buffer $\left(\mathrm{K}_{2} \mathrm{HPO}_{4} / \mathrm{KH}_{2} \mathrm{PO}_{4}\right.$; $\mathrm{pH}$ 7) and transferred to a test-tube containing $100 \mu \mathrm{l}$ of $1 \%$ (v/v) Triton X-100 (Sigma-Aldrich, Dorset, UK). One hundred $\mu \mathrm{l}$ of $\mathrm{H}_{2} \mathrm{O}_{2}$ were then added to each test tube. The formation of oxygen bubbles, as a result of the enzymatic degradation of $\mathrm{H}_{2} \mathrm{O}_{2}$, was visualised in the form of foam. After 5 min the height of the foam was measured and photographic images were taken as well. All experiments were performed on six independent biological replicates.

\subsection{Statistical analysis}

In all cases, experiments were run at least in triplicate, and results were assessed with a paired

Student $\mathrm{T}$-test. A p value lower than 0.05 was considered statistically significant.

\section{Results}

\subsection{Survival against hydrogen peroxide}

L. monocytogenes strains (10403S, EGD-e and LO28) WT and the respective deletion mutants in the different genes of the GAD system, were challenged with $\mathrm{H}_{2} \mathrm{O}_{2}$. In L. monocytogenes 10403S, the WT strain showed approximately $3 \log$ reduction of CFU/ml after being challenged with $\mathrm{H}_{2} \mathrm{O}_{2}$ (Fig. 1A) which did not show any statistically significant difference compared to any 
of its isogenic mutants $\left(\Delta \operatorname{gadD} 1, \Delta \operatorname{gadD} 2, \Delta \operatorname{gadD3}, \Delta l m r g \_02013\right)$ despite $\Delta$ gadD3 showing a

$4.6 \log$ reduction of $\mathrm{CFU} / \mathrm{ml}$.

In L. monocytogenes EGD-e, all GAD mutants showed lower survival than the WT against an oxidative stress (Fig. 1B) but only $\Delta g a d D 2$ and $\Delta g a d D 3$ showed statistical significance. Sixty min after being challenged with $\mathrm{H}_{2} \mathrm{O}_{2}$, the WT strain showed $0.5 \log$ reduction of $\mathrm{CFU} / \mathrm{ml}$, while the GAD mutants $\Delta g a d D 1, \Delta g a d D 2, \Delta g a d D 3$ and $\Delta l m o 0913$ showed a reduction of 2.4, 3.5, 4.8 and $2 \log \mathrm{CFU} / \mathrm{ml}$ respectively. However, despite the major differences relatively to the WT, only these for $\Delta g a d D 2$ and $\Delta g a d D 3$ were statistically significant.

In L. monocytogenes LO28, only the $\Delta$ gadD1 showed a significant reduction of $5.67 \mathrm{log}$ $\mathrm{CFU} / \mathrm{ml}(\mathrm{p}=0.01)$ after exposure to $\mathrm{H}_{2} \mathrm{O}_{2}$ in comparison to a reduction of $1.05 \log \mathrm{CFU} / \mathrm{ml}$ for the WT (Fig. 1C). Interestingly, both $\Delta g a d D 2$ and the double mutant that lacks both glutamate decarboxylases, $\Delta \operatorname{gad} D 1 / D 2$, showed negligible difference relatively to the WT.

\subsection{Hydrogen Peroxide Disk Diffusion Assay}

Disk diffusion assays were performed in all three WT strains and their respective isogenic mutants missing GAD system genes. L. monocytogenes EGD-e $\triangle$ gadD1 and $\triangle$ gadD3 showed larger inhibition zones relatively to the WT ( $p=0.04$ and $p=0.001$ respectively; Fig. 2). All the remaining GAD mutants, both in $10403 \mathrm{~S}$ and LO28, showed no significantly different growth inhibition in comparison with the WT.

\subsection{Catalase Assay}

The catalase activity was assessed in L. monocytogenes 10403S, EGD-e and LO28 WT and their respective isogenic mutants missing GAD system genes (Fig. 3), using a visual approach. Briefly, the degradation of $\mathrm{H}_{2} \mathrm{O}_{2}$ by catalase produces water and molecular oxygen that is released and forms a foam. It has been demonstrated previously that the height of the foam is directly proportional to the catalase activity (Iwase et al., 2013). The activity of catalase in EGD-e $\Delta g a d D 3$ was significantly reduced comparatively to the WT ( $\mathrm{p}=0.01$ ). No statistically 
$10403 \mathrm{~S}$ and LO28 or in the remaining mutants in EGD-e. However, in LO28 the $\Delta$ gadD2 and

227

228

229

230

231

232

233

234

235

236

237

238

$\Delta$ gadD1/2 seemed to have slightly higher catalase activity than the WT.

\subsection{Effect of $\mathrm{H}_{2} \mathrm{O}_{2}$ on growth}

The effect $\mathrm{H}_{2} \mathrm{O}_{2}$ on the growth of L. monocytogenes WT and the respective GAD mutants was assessed by inoculating the bacterial cultures in the presence of $0.01 \%$ of $\mathrm{H}_{2} \mathrm{O}_{2}$ and monitoring the absorbance at $620 \mathrm{~nm}\left(\mathrm{OD}_{620}\right)$.

As expected, growth in the presence of $\mathrm{H}_{2} \mathrm{O}_{2}$ caused a significant extension in the lag phase of all WT strains and mutants in study (comparison with and without $\mathrm{H}_{2} \mathrm{O}_{2}$; Table 2). The maximum growth $\left(\max \mathrm{OD}_{620}\right)$ was only significantly decreased in LO28 WT and the corresponding $\Delta$ gadD2 (Table 3).

In the absence of $\mathrm{H}_{2} \mathrm{O}_{2}$, none of the mutants showed a significant difference in the growth parameters in comparison to the WT. However, in the presence of $\mathrm{H}_{2} \mathrm{O}_{2}$ some of the GAD mutants showed alterations of the growth parameters, in comparison with the parental WT strain. In both $10403 \mathrm{~S}$ (Fig. 4) and EGD-e (Fig. 5), the $\Delta$ gadD3 had a significant delay in the lag phase (Table 2), while in LO28 (Fig. 6) the $\Delta g a d D 1$ and $\Delta g a d D 1 / 2$ showed a significant decrease of the $\max \mathrm{OD}_{620}$ (Table 3).

\section{Discussion}

Oxidative stress resistance is very important for survival of L. monocytogenes in foods, food preparation environments and finally in its ability to cause disease. Various disinfectants, ozone treatments, cold plasma or sonication are used or investigated to eliminate microbes and pathogens such as L. monocytogenes through the application of oxidative stress in foods or food preparation environments (Cabiscol et al., 2000; Imlay, 2003; Jaksch et al., 2004; O’Byrne and Karatzas, 2008; O’Donnell et al., 2012). Understanding the behaviour of this pathogen in oxidative environments is important for our ability to design effective treatments, especially as 
252 some of these novel techniques such as cold plasma and sonication have not yet found their way

253 in the food industry.

254 Furthermore, oxidative stress resistance plays a role in the pathogenesis of intracellular 255 pathogens as oxidative stress occurs in the phagocytic lysosome. However, up to now, there is no evidence showing that in L. monocytogenes. In contrast, our work suggests the opposite, as hypersensitive to oxidative stress $L$. monocytogenes $\Delta \operatorname{sig} B$ mutants, have similar intracellular 258 proliferation to their corresponding WT (Boura et al., 2016). In the latter work we also 259 demonstrated that SigB, the main stress gene regulator in L. monocytogenes, affects oxidative stress resistance in a different fashion to other stresses (Boura et al., 2016). Although upregulation of $\operatorname{sig} B$ enhances general resistance to multiple stresses, it results in hypersensitivity to oxidative stress and this occurs through lower catalase activity. It is not known how SigB affects catalase (Boura et al., 2016). It is possible that SigB negatively affects oxidative stress resistance through regulation of another mechanism, which in turn affects catalase and possibly other oxidative stress mechanisms. The L. monocytogenes GAD system is under the control of SigB (Wemekamp-Kamphuis et al., 2004) while in the Gram-negative bacterium, Francisella tularensis (Ramond et al., 2014), the yeast Saccharomyces cerevisiae (Coleman et al., 2001) and the animal cells astrocytes (Bellier et al., 2000; Lamigeon et al., 2001) it has been implicated in oxidative stress resistance. We thought of the possiblity that the GAD system could mediate the effect of $\operatorname{SigB}$ to catalase and oxidative stress in $L$. monocytogenes. However, this theory is problematic because in L. monocytogenes, SigB upregulates the GAD system (Wemekamp-Kamphuis et al., 2004), and based on the results obtained in these three aforementioned organisms, it should be expected that SigB-mediated GAD system upregulation results in the opposite effect (enhancement of oxidative stress resistance) from what is actually observed (hypersensitivity to oxidative stress). In addition, none of the above organisms except $L$. monocytogenes possesses a $\operatorname{sig} B$ gene, while the GAD system effects on oxidative stress have been only observed in three organisms so far and only once in a bacterium which is Gram-negative. 
279 Despite the above, we decided to assess for first time the role of the Listeria monocytogenes

280 GAD system in oxidative stress. We looked first at the role of the different GAD system genes

281 in oxidative stress tolerance, in three common reference L. monocytogenes strains namely,

282 10403S, LO28, EGD-e which reflect the major differences between different strains of $L$.

283 monocytogenes in terms of GAD system activity which significantly affects acid resistance. $L$. monocytogenes $10403 \mathrm{~S}$ possesses one of the most active GAD systems resulting in one of the most acid resistant phenotypes described in the literature, LO28 has a normal GAD activity and acid resistance, while EGD-e has a defective $\mathrm{GAD}_{\mathrm{e}}$ system unable to export GABA and it is one of the most acid sensitive strains described in the literature (Karatzas et al., 2012).

The GAD system is the major determinant of acid resistance in L. monocytogenes and many other organisms (Cotter et al., 2001; Ryan et al., 2008) with mutants in GAD genes showing severe impairment in acid resistance (Paudyal et al., 2018). The GAD system comprises two distinctive subsystems, which are defined by the original location of glutamate utilised by the GAD system. Our group has previously described the extracellular GAD system $\left(G_{A D}\right)$, which is the one investigated in vast majority of publications, utilising extracellular glutamate imported by the GAD glutamate/GABA antiporter and the intracellular GAD system $\left(\mathrm{GAD}_{\mathrm{i}}\right)$, which utilises glutamate transported by glutamate transporter(s) or that produced by metabolic pathways (Karatzas et al. 2012).

In the present study we show for first time that the GAD system affects oxidative stress in a Gram-positive bacterium (L. monocytogenes) and this is the second account in any bacterium. We found that gadD3 deletion resulted in a decrease in survival against oxidative stress in EGD-e (Fig. 1B) and growth inhibition (lag phase extension) in both EGD-e and 10403S (Table 2) and larger inhibition zone in EGD-e (Fig. 2). Unfortunately, it was impossible for other workers and for us to obtain a $\Delta g a d D 3$ mutant in the LO28 background (Cotter et al. 2005). Results clearly highlight the role of GadD3 in oxidative cell defence. GadD3 only contributes to the $\mathrm{GAD}_{\mathrm{i}}$ system (Karatzas et al., 2012) but not to the $\mathrm{GAD}_{\mathrm{e}}$ system as it is not associated with any antiporter and it does not affect the GABA export. The $\mathrm{GAD}_{\mathrm{i}}$ plays an important role in acid tolerance and in EGD-e it is the only functional GAD system component, while it 
contributes in acid resistance in other strains that use the $\mathrm{GAD}_{\text {e }}$ (e.g. 10403S; Karatzas et al., 2012).

Another GAD gene that affected oxidative stress resistance was gadD1. Deletion of this gene resulted in lower survival in LO28 (Fig. 1C) and larger inhibition zone in EGD-e (Fig. 2) underpinning its role in oxidative stress defence. It has been suggested previously that GadD1 plays a role in growth under mildly acidic conditions, as strains that belong to serotype 4 lack gadD1 and grow poorly at pH 5.1 (Cotter et al., 2005). This however, might not be solely the result of the lack of gadDl but the result of other genetic differences in this serotype. In addition, following various attempts we have never detected GABA being exported by GadD1T1, while a mutant lacking gadD1 has a comparable survival to its corresponding WT under acidic conditions (Karatzas et al., 2012; Cotter et al., 2005). All these suggest that the role of gadD1 in acid resistance is debatable however, it has a clear role in tolerance of LO28 against nisin, which has been suggested to stem from its contribution to ATP production as its absence resulted in 60\% reduction of ATP pools (Begley et al., 2010). ATP levels in L. monocytogenes are critical for survival against nisin (Bonnet et al., 2006). Interestingly, a study in astrocytes found that GAD-expressing cells not only produced more ATP (Bellier et al., 2000) but also had increased ability to cope with oxidative stress (Lamigeon et al., 2001). We expected that also the double LO28 mutant lacking both gadD1 and gadD2 ( $\operatorname{gadD1/D2})$ should demonstrate a similar phenotype since $\Delta g a d D 2$ showed no phenotype to $\Delta g a d D 1$ in this background. However, this was not the case with $\Delta g a d D 1 / D 2$ which showed a similar phenotype to WT and $\Delta g a d D 2$ (Fig. 1C). It has been commented previously for acid resistance that $\Delta g a d D 1 / D 2$ could result in an unknown response which could counteract the double deletion (Feehily et al., 2014) and possibly explain the lack of phenotype in this mutant.

330 We also assessed the role of gadD2 gene in oxidative stress and we found that its deletion 331 affected survival in EGD-e (Fig. 1B). GadD2 is the main component of the $\mathrm{GAD}_{\mathrm{e}}$ system, which however, is inactive in EGD-e resulting in a highly acid sensitive phenotype in this strain 
334 defect in the decarboxylase GadD2 or the antiporter GadT2. Since our results show a phenotype

335 for $\Delta \operatorname{gadD2}$, this could suggest that GadD2 is active in EGD-e utilising only intracellular

336 glutamate as part of the $\mathrm{GAD}_{\mathrm{i}}$ system and a possible defect in the GadT2 antiporter prevents

337 glutamate/GABA antiport activity. Although GadD2 is highly active especially in $10403 \mathrm{~S}$ and

338 in LO28 we did not see any phenotype, which might be related with the fact that these strains are not highly resistant to oxidative stress and changes in oxidative stress resistant mechanisms might not bring major changes in the phenotypes. This might also explain why all GAD mutants in EGD-e, which is the most resistant strain to oxidative stress (Boura et al., 2016), showed lower survival than the WT, with only in $\Delta g a d D 3$ and $\Delta g a d D 2$ however, showing statistical significance. Furthermore, our results show that the GAD genes that might play a role in survival against $\mathrm{H}_{2} \mathrm{O}_{2}$ in one strain, might be different from the ones playing a role in growth in broth or agar in the presence of $\mathrm{H}_{2} \mathrm{O}_{2}$. This might be due to the fact that survival assays assessed oxidative defences at a different growth stage from disk diffusion and growth experiments, while the latter two were also performed in different media phases (liquid or solid agar) resulting in different responses (Boura et al., 2016).

Furthermore, it should be mentioned that all phenotypes seem to be associated with glutamate decarboxylases working on intracellular glutamate and therefore, contributing only to the $\mathrm{GAD}_{\mathrm{i}}$ but not to the $\mathrm{GAD}_{\mathrm{e}}$ system.

The $\mathrm{GAD}_{\mathrm{i}}$ system results in the production of intracellular GABA which is metabolised through the GABA shunt (Fig. 7). The latter pathway contributes to the maintenance of the intracellular pools of NADPH and other anti-oxidant molecules (Bellier et al., 2000; Feehily et al., 2013; Lamigeon et al., 2001; Ramond et al., 2014) which could be involved in the oxidative stress resistance and maybe explain the observed phenotypes. In Francisella tularensis, oxidative stress resistance is important for replication in the cytosol of infected cells and the GadC antiporter is crucial for this process and the escape from the phagosome compartment (Ramond et al., 2014). The authors suggest that a decrease of glutamate acquisition results in a reduction of tricarboxylic acid (TCA) cycle intermediates with potent anti-oxidant effect, such as oxoglutarate and NADPH, produced by the conversion of glutamate into oxoglutarate (Ramond 
et al., 2014). Reduced NADPH pools could also result in the reduction of glutathione, a potent antioxidant tripeptide with a well-known role in oxidative stress tolerance, since NADPH functions as a co-factor of the glutathione reductase (Smirnova and Oktyabrsky, 2017; Vogel et al., 1999). A similar hypothesis was postulated to explain the increased resistance of GADexpressing astrocyte cells (Lamigeon et al., 2001) which was the result of a 10-fold increase in the levels of released glutathione (Lamigeon et al., 2001), and of increased NADPH and ATP levels (Bellier et al., 2000). Furthermore, a study in Saccharomyces cerevisiae, showed that the presence of a functional GAD system and GABA shunt pathway, are essential for oxidative stress resistance (Coleman et al., 2001) which is expected as GABA shunt contributes in NADPH pools (Ramos et al., 1985).

To investigate the above hypothesis that the GABA shunt plays a role in oxidative stress and can explain the above phenotypes in L. monocytogenes, we employed mutants lacking succinate semialdehyde dehydrogenase (SSDH), the second step of the GABA shunt, in two different backgrounds; EGD-e ( $\Delta l m o 0913)$ and 10403S (Almrg_02013). Deletion of SSDH resulted in no phenotype in $10403 \mathrm{~S}$ and a slight effect in the EGD-e background (2 log cycles of CFU/ml further reduction compared to WT) without any statistical significance. We have previously shown that Lmo0913 and Lmrg_02013 are the only SSDH proteins in EGD-e and 10403S L. monocytogenes backgrounds respectively, as both mutants were defective in SSDH activity (Feehily et al., 2013). Given that the SSDH reaction results in NADPH production that contributes in oxidative stress resistance, the absence of a strong phenotype from both SSDH mutants is surprising (Fig. 7). Furthermore, since this oxidative stress resistance is directly associated with the $\mathrm{GAD}_{\mathrm{i}}$ which directly feeds $\mathrm{GABA}$ into the GABA shunt it should be expected that its disruption would result in a phenotype which is not the case. We can not exclude the possibility that GABA shunt plays a role in oxidative stress resistance, but this might happen through the GABA transaminase, the first step of the GABA shunt pathway, which affects the TCA cycle by removing a-ketoglutaric acid that is converted to glutamate (Fig. 7). Furthermore, it should be considered that the GABA shunt in L. monocytogenes and various other bacteria (e.g. several lactic acid bacteria) plays an important role as it bypasses 
two missing steps of the TCA cycle while other organisms have a complete TCA cycle (Fig. 7).

391 Further work is required to identify the actual link between the GAD system - GABA shunt and oxidative stress possibly focusing on GABA transaminase.

We further looked at the mechanism resulting in these phenotypes by investigating the catalase activity of these mutants. We found a statistically significant decrease in catalase activity of $\triangle$ gadD3 in EGD-e, which correlated with the lower survival of this strain under oxidative stress

(Fig. 3). However, the same was not observed in LO28 $\Delta$ gadD1, which also showed a marked reduction in survival. Despite catalase being the main pathway of $\mathrm{H}_{2} \mathrm{O}_{2}$ degradation, there are other antioxidant molecules, such as NADPH and NADH pools, ascorbic acid etc. that help to maintain an intracellular reducing environment (Cabiscol et al., 2000).

It should also be mentioned that experiments in this study were performed in native $\mathrm{pH}$ ( 6.4 for L. monocytogenes in stationary phase), where the GAD system is not in its maximum activity level, which occurs between $\mathrm{pH} 4$ and 5 (Karatzas et al., 2012). It is possible that at lower pH these phenotypes might be more enhanced. However, we did not use these conditions to avoid the application of an additional stress to the bacteria, as it is known that the mutants of the GAD system are sensitive to acidic conditions, and this additional stress could have a significant impact in understanding their role in oxidative stress response (Paudyal et al., 2018).

It should be mentioned that this work could have major implications for applications of oxidative stress in the food industry and hurdle technology. Modern hurdle technology design could be based on knowledge of the molecular bacterial mechanisms to predict bacterial behaviour, instead of randomly looking at combinations of stresses. We have exemplified this in our previous work where we demonstrated that the use of a GAD system inhibitor such as maleic acid, could render L. monocytogenes cells highly sensitive to acidic stress and eliminate them in disinfection regimes (Paudyal et al., 2018). Our work here shows that the GAD system, the main acid resistance mechanism in L. monocytogenes, protects against oxidative stress, suggesting that downregulation or inhibition through a signal could make cells highly sensitive to oxidative stress processes and further work should demonstrate that in various oxidative stress food applications. In addition, further work also needs to look if this this involvement of 
418 the GAD system in oxidative stress is a common characteristic among other bacteria and other

419 organisms and identify the molecular mechanisms involved in this phenomenon further to the

420 ones described in this manuscript.

421

\section{5. Conclusions}

423 Overall, our results suggest that the $\mathrm{GAD}_{\mathrm{i}}$ in L. monocytogenes plays a role in survival and 424 growth under oxidative stress. This is concluded since, all GAD genes affecting oxidative stress 425 resistance ( $g a d D 3$ and $\operatorname{gadD} 2$ in EGD-e, gadD1 in LO28) or tolerance during growth ( $\mathrm{gadD} 3$ in 10403S, gadD1 and gadD3 in EGD-e) are all part of the $\mathrm{GAD}_{\mathrm{i}}$ system. Furthermore, in an attempt to assess if these effects are through the GABA shunt we show that, if this is the case, it rather occurs through the GABA-AT step and not through SSDH step as disruption of the latter step did not result in a phenotype linked with oxidative stress resistance.

430 The targeted inhibition of the GAD system, as a way to make L. monocytogenes more sensitive to acid stress has been recently exploited as a promising tool to eliminate this pathogen (Paudyal et al., 2018; Paudyal and Karatzas, 2016) and similar steps could be taken in hurdle technology using oxidative stress. Furthermore, additional work should be carried out in other microorganisms that possess the GAD system, to identify if GAD system affects oxidative stress resistance.

\section{Acknowledgments}

The authors would like to thank all colleagues at the Microbiology research team and the Department of Food and Nutritional Sciences, University of Reading. The work was supported by a Marie Curie European Reintegration Grant (ERG 265154), awarded to Dr. K.A.G. Karatzas and funds from the University of Reading.

\section{References}

445 Allerberger, F., Wagner, M., 2010. Listeriosis: A resurgent foodborne infection. Clin. 
Baranyi, J., Roberts, T.A., 1994. A dynamic approach to predicting bacterial growth in food. Int. $1605(94) 90157-0$

450

Baranyi, J., Ross, T., McMeekin, T.A., Roberts, T.A., 1996. Effects of parameterization on the performance of empirical models used in "predictive microbiology." Food Microbiol. 13, 83-91. https://doi.org/https://doi.org/10.1006/fmic.1996.0011

Begley, M., Cotter, P.D., Hill, C., Ross, R.P., 2010. Glutamate decarboxylase-mediated nisin resistance in Listeria monocytogenes. Appl. Environ. Microbiol. 76, 6541-6546. https://doi.org/10.1128/AEM.00203-10

Bellier, J.P., Sacchettoni, S., Prod'hon, C., Perret-Liaudet, A., Belin, M.F., Jacquemont, B., 2000. Glutamic acid decarboxylase-expressing astrocytes exhibit enhanced energetic metabolism and increase PC12 cell survival under glucose deprivation. J. Neurochem. 75, $56-64$.

Bonnet, M., Rafi, M.M., Chikindas, M.L., Montville, T.J., 2006. Bioenergetic mechanism for nisin resistance, induced by the acid tolerance response of Listeria monocytogenes. Appl. Environ. Microbiol. 72, 2556-2563. https://doi.org/10.1128/AEM.72.4.2556-2563.2006

Boura, M., Keating, C., Royet, K., Paudyal, R., O’Donoghue, B., O’Byrne, C.P., Karatzas, K.A.G., 2016. The presence of SigB in Listeria monocytogenes strains EGD-e and 10403S leads to hypersensitivity to hydrogen peroxide in stationary phase under aerobic $\begin{array}{llll}\text { conditions. } & \text { Appl. } & \text { Environ. } & \text { Microbiol. }\end{array}$ https://doi.org/10.1128/AEM.00709-16

Cabiscol, E., Tamarit, J., Ros, J., 2000. Oxidative stress in bacteria and protein damage by reactive oxygen species. Int. Microbiol. 3, 3-8.

Cole, M.B., Jones, M. V, Holyoak, C., 1990. The effect of pH, salt concentration and temperature on the survival and growth of Listeria monocytogenes. J. Appl. Bacteriol. 69, $63-72$.

Coleman, S.T., Fang, T.K., Rovinsky, S. a., Turano, F.J., Moye-Rowley, W.S., 2001. 
Expression of a glutamate decarboxylase homologue is required for normal oxidative stress tolerance in Saccharomyces cerevisiae. J. Biol. Chem. 276, 244-250. https://doi.org/10.1074/jbc.M007103200

477

Cotter, P.D., Gahan, C.G.M., Hill, C., 2001. A glutamate decarboxylase system protects Listeria monocytogenes in gastric fluid. Mol Microbiol. 40(2), 465-75.

480 https://doi.org/10.1046/j.1365-2958.2001.02398.x

Cotter, P.D., Ryan, S., Gahan, C.G.M., Hill, C., 2005. Presence of GadD1 glutamate

Feehily, C., 2014. Elucidation of the role of the glutamate decarboxylase system and the $\gamma$ aminobutyric acid shunt pathway in the stress response of Listeria monocytogenes. NUI Galway Theses. https://aran.library.nuigalway.ie/handle/10379/4628

Feehily, C., Finnerty, A., Casey, P.G., Hill, C., Gahan, C.G.M., O’Byrne, C.P., Karatzas, K.A.G., 2014. Divergent evolution of the activity and regulation of the glutamate decarboxylase systems in Listeria monocytogenes EGD-e and 10403S: Roles in virulence and acid tolerance. PLoS One 9, e112649. https://doi.org/10.1371/journal.pone.0112649

Feehily, C., Karatzas, K. A G., 2013. Role of glutamate metabolism in bacterial responses towards acid and other stresses. J. Appl. Microbiol. 114, 11-24. https://doi.org/10.1111/j.1365-2672.2012.05434.x

Feehily, C., O’Byrne, C.P., Karatzas, K.A.G., 2013. Functional $\gamma$-aminobutyrate shunt in Listeria monocytogenes: role in acid tolerance and succinate biosynthesis. Appl. Environ. Microbiol. 79, 74-80. https://doi.org/10.1128/AEM.02184-12

Imlay, J.A., 2003. Pathways of oxidative damage. Annu. Rev. Microbiol. 57, 395-418. https://doi.org/10.1146/annurev.micro.57.030502.090938

Iwase, T., Tajima, A., Sugimoto, S., Okuda, K., Hironaka, I., Kamata, Y., Takada, K., Mizunoe, Y., 2013. A simple assay for measuring catalase activity: A visual approach. Sci. Rep. 3, 3081. https://doi.org/10.1038/srep03081 
502 Jaksch, D., Margesin, R., Mikoviny, T., Skalny, J.D., Hartungen, E., Schinner, F., Mason, N.J.,

503 Märk, T.D., 2004. The effect of ozone treatment on the microbial contamination of pork

504 meat measured by detecting the emissions using PTR-MS and by enumeration of

505 microorganisms. Int. J. Mass Spectrom. 239, 209-214.

506 Karatzas, K.A.G., Suur, L., O’Byrne, C.P., 2012. Characterization of the intracellular glutamate

507 decarboxylase system: Analysis of its function, transcription, and role in the acid

508 resistance of various strains of Listeria monocytogenes. Appl. Environ. Microbiol. 78,

509 3571-3579. https://doi.org/10.1128/AEM.00227-12

510 Karatzas, K.A.G., Brennan, O., Heavin, S., Morrissey, J., O’Byrne, C.P., 2010. Intracellular 511 accumulation of high levels of gamma-aminobutyrate by Listeria monocytogenes 10403S

512 in response to low $\mathrm{pH}$ uncoupling of gamma-aminobutyrate synthesis from efflux in a chemically defined medium. Appl. Environ. Microbiol. 76, 3529-3537. https://doi.org/10.1128/AEM.03063-09

Kinnersley, A.M., Turano, F.J., 2000. $\gamma$-aminobutyric acid (GABA) and plant responses to stress, Crit. Rev. Plant Sci. 19:6, 479-509. doi: 10.1080/07352680091139277

517 Lamigeon, C., Bellier, J.P., Sacchettoni, S., Rujano, M., Jacquemont, B., 2001. Enhanced neuronal protection from oxidative stress by coculture with glutamic acid decarboxylaseexpressing astrocytes. J. Neurochem. 77, 598-606. https://doi.org/10.1046/j.14714159.2001.00278.x

Mcclure, P.J., Roberts, T.A., Oguru, P.O., 1989. Comparison of the effects of sodium chloride,

Mead, P.S., Slutsker, L., Dietz, V., McCaig, L.F., Bresee, J.S., Shapiro, C., Griffin, P.M., 
O’Byrne, C.P., Karatzas, K.A.G., 2008. The role of Sigma B $\left(\sigma^{\mathrm{B}}\right)$ in the stress adaptations of Listeria monocytogenes: overlaps between stress adaptation and virulence, Adv. Appl. Microbiol. Elsevier Masson SAS.

O’Donnell, C., Tiwari, B.K., Cullen, P.J., Rice, R.G., 2012. Ozone in Food Processing. WileyBlackwell.

Paudyal, R., Barnes, R.H., Karatzas, K.A.G., 2018. A novel approach in acidic disinfection through inhibition of acid resistance mechanisms; Maleic acid-mediated inhibition of glutamate decarboxylase activity enhances acid sensitivity of Listeria monocytogenes. Food Microbiol. 69, 96-104. https://doi.org/10.1016/j.fm.2017.07.013

Paudyal, R., Karatzas, K.A., 2016. Stress adaptation of Listeria monocytogenes in acidic readyto-eat products, Food Hygiene and Toxicology in Ready-to-Eat Foods. Elsevier Inc. https://doi.org/10.1016/B978-0-12-801916-0.00010-8

Petroff, O.A.C., 2002. Book Review: GABA and Glutamate in the Human Brain. Neurosci. 8, 562-573. https://doi.org/10.1177/1073858402238515

Ramond, E., Gesbert, G., Rigard, M., Dairou, J., Dupuis, M., Dubail, I., Meibom, K., Henry, T., Barel, M., Charbit, A., 2014. Glutamate utilization couples oxidative stress defense and the tricarboxylic acid cycle in Francisella phagosomal escape. PLoS Pathog. 10.

Ryan, S., Hill, C., Gahan, C.G.M., 2008. Acid Stress Responses in Listeria monocytogenes, in: Adv. Appl. Microbiol. pp. 67-91. https://doi.org/10.1016/S0065-2164(08)00603-5 https://doi.org/10.1007/s10541-005-0248-3

557 Smith, D.K., Kassam, T., Singh, B., Elliott, J.F., 1992. Escherichia coli has two homologous 
559 Vogel, R., Wiesinger, H., Hamprecht, B., Dringen, R., 1999. The regeneration of reduced 560 glutathione in rat forebrain mitochondria identifies metabolic pathways providing the $561 \quad$ NADPH required. Neurosci. Lett. 275, 97-100.

562

563

564

Walsh, S., Diamond, D., 1995. Non-linear curve fitting using Microsoft Excel solver. Talanta 42, 561-572. https://doi.org/https://doi.org/10.1016/0039-9140(95)01446-I

Wemekamp-Kamphuis, H.H., Wouters, J.A., de Leeuw, P.P., Hain, T., Chakraborty, T., Abee, T. 2004. Identification of sigma factor sigma B-controlled genes and their impact on acid stress, high hydrostatic pressure, and freeze survival in Listeria monocytogenes EGD-e. Appl Environ Microbiol. https://doi.org/10.1128/AEM.70.6.3457-3466.2004.

Zhu, L., Peng, Q., Song, F., Jiang, Y., Sun, C., Zhang, J., Huang, D., 2010. Structure and regulation of the gab gene cluster, involved in the $\gamma$-aminobutyric acid shunt, are controlled by a sigma54 factor in Bacillus thuringiensis. J. Bacteriol. 192, 346-55. https://doi.org/10.1128/JB.01038-09

\section{Legends to the Figures}

Fig. 1. Survival of Listeria monocytogenes 10403S (A), EGD-e (B) and LO28 (C) WT and respective GAD mutants, after being challenged with $4 \%$ (A and C) or $4.5 \%$ (B) $\mathrm{H}_{2} \mathrm{O}_{2}$. DL denotes the detection limit of the assay. The error bars represent standard deviations of triplicate observations (biological replicates) and asterisks denote statistically significance relatively to the WT.

Fig. 2. Catalase activity of Listeria monocytogenes 10403S, EGD-e and LO28 WT and respective GAD mutants. Asterisks denote statistically significance and the error bars represent standard deviations. 
586 Fig. 3. Growth inhibition zone (diameter, mm) of L. monocytogenes 10403S, EGD-e and LO28

587 WT and respective isogenic mutants of the GAD, in diffusion assay using $30 \% \mathrm{H}_{2} \mathrm{O}_{2}$. Asterisks

588 denote statistically significance and the error bars represent standard deviations.

589

590 Fig. 4. Effect of sub-lethal concentration of $\mathrm{H}_{2} \mathrm{O}_{2}$ on L. monocytogenes 10403S WT (A), $591 \Delta$ gadD1 (B), $\Delta$ gadD2 (C), $\Delta$ gadD3 (D), $\Delta l m r g \_02013$ (E) growth (squared symbols, red line).

592 As a control 10403s cells grown with no $\mathrm{H}_{2} \mathrm{O}_{2}$ were used (round symbols, black lines). Symbols 593 represent individual data points of three independent experiments and lines the respective fit 594 curve.

595

596 Fig. 5. Effect of sub-lethal concentration of $\mathrm{H}_{2} \mathrm{O}_{2}$ on L. monocytogenes EGD-e WT (A), 597 $\Delta \operatorname{gadD1}(\mathrm{B}), \Delta \operatorname{gadD} 2(\mathrm{C}), \Delta \operatorname{gadD} 3(\mathrm{D}), \Delta \operatorname{lmo0913}(\mathrm{E})$ growth (squared symbols, red line). As a control EGD-e cells grown with no $\mathrm{H}_{2} \mathrm{O}_{2}$ were used (round symbols, black lines). Symbols represent individual data points of three independent experiments and lines the respective fit curve.

601

602

Fig. 6. Effect of sub-lethal concentration of $\mathrm{H}_{2} \mathrm{O}_{2}$ on L. monocytogenes LO28 WT (A), $\Delta$ gadD1 603 (B), $\Delta$ gadD2 (C), $\Delta$ gadD1/D2 (D) growth (squared symbols, red line). As a control LO28 cells grown with no $\mathrm{H}_{2} \mathrm{O}_{2}$ were used (round symbols, black lines). Symbols represent individual data points of three independent experiments and lines the respective fit curve.

606

607 Fig. 7. Overview of chemical reactions carried out by the extracellular and intracellular GAD 608 system $\left(\mathrm{GAD}_{\mathrm{e}}\right.$ and $\mathrm{GAD}_{\mathrm{i}}$ respectively) the GABA shunt and the TCA cycle. GABA-AT is 609 GABA aminotransferase and SSDH is succinate semialdehyde dehydrogenase. 


\section{Tables}

Table 1. Strains used in this study

\begin{tabular}{|c|c|c|}
\hline Strains & Relevant properties & $\begin{array}{l}\text { Reference/ } \\
\text { Source }\end{array}$ \\
\hline $10403 \mathrm{~S}$ & Serotype $1 / 2$ a, wild type & (Karatzas et al., 2010) \\
\hline 10403S $\Delta$ gadDl & $10403 \mathrm{~S}$ with an in-frame deletion of $\mathrm{gadD} 1$ & (Feehily et al., 2014) \\
\hline $10403 \mathrm{~S} \Delta \mathrm{gadD} 2$ & $10403 \mathrm{~S}$ with an in-frame deletion of gadD2 & (Feehily et al., 2014) \\
\hline 10403S $\Delta$ gadD3 & $10403 \mathrm{~S}$ with an in-frame deletion of gadD3 & (Feehily et al., 2014) \\
\hline 10403S $\Delta l m r g \_02013$ & $\begin{array}{l}\text { 10403S with an in-frame deletion of } \\
\text { lmrg_02013 }\end{array}$ & (Feehily, 2014) \\
\hline EGD-e & Serotype $1 / 2$ a, wild type & $\begin{array}{c}\text { (Feehily, 2014; Murray et } \\
\text { al., 1926) }\end{array}$ \\
\hline EGD-e $\Delta \operatorname{gad} D 1$ & EGD-e with an in-frame deletion of gadD1 & (Feehily, 2014) \\
\hline EGD-e $\Delta$ gadD2 & EGD-e with an in-frame deletion of gadD2 & (Feehily, 2014) \\
\hline EGD-e $\Delta \operatorname{gadD} 3$ & EGD-e with an in-frame deletion of gadD3 & (Feehily, 2014) \\
\hline EGD-e $\Delta l m o 0913$ & EGD-e with an in-frame deletion of $\operatorname{lmo} 0913$ & (Feehily et al., 2013) \\
\hline LO28 & Serotype $1 / 2 c$, wild type & (Cotter et al., 2001) \\
\hline $\mathrm{LO} 28 \Delta \operatorname{gadD} 1$ & LO28 with an in-frame deletion of $g a d D 1$ & (Cotter et al., 2001) \\
\hline $\mathrm{LO} 28 \Delta \operatorname{gadD} 2$ & LO28 with an in-frame deletion of gadD2 & (Cotter et al., 2001) \\
\hline $\mathrm{LO} 28 \Delta \operatorname{gadD} 1 / \mathrm{D} 2$ & $\begin{array}{l}\text { LO28 with an in-frame deletion of } g a d D 1 \text { and } \\
\text { gadD2 }\end{array}$ & (Cotter et al., 2001) \\
\hline
\end{tabular}

* All above genes encode glutamate decarboxylases except for lmo0913 and lmrg_02013 which encode a succinate semialdehyde dehydrogenase in EGD-e and 10403S strains respectively. 
Table 2. Duration of lag phase (in hours) of L. monocytogenes strains grown in the presence (+) or absence (-) of $\mathrm{H}_{2} \mathrm{O}_{2}$.

\begin{tabular}{|c|c|c|c|c|c|c|}
\hline Lag phase & \multicolumn{2}{|c|}{ 10403S } & \multicolumn{2}{|c|}{ EGD-e } & \multicolumn{2}{|c|}{ LO28 } \\
\hline & $\mathrm{H}_{2} \mathrm{O}_{2}(+)$ & $\mathrm{H}_{2} \mathrm{O}_{2}(-)$ & $\mathrm{H}_{2} \mathrm{O}_{2}(+)$ & $\mathbf{H}_{2} \mathbf{O}_{2}(-)$ & $\mathrm{H}_{2} \mathrm{O}_{2}(+)$ & $\mathrm{H}_{2} \mathrm{O}_{2}(-)$ \\
\hline WT & $\begin{array}{l}5.11 \\
( \pm 0.52)\end{array}$ & $\begin{array}{l}2.66 \quad(\dagger) \\
( \pm 0.20)\end{array}$ & $\begin{array}{l}4.49 \\
( \pm 0.11)\end{array}$ & $\begin{array}{l}2.92(\dagger) \\
( \pm 0.01)\end{array}$ & $\begin{array}{l}6.60 \\
( \pm 0.32)\end{array}$ & $\begin{array}{l}3.71 \quad(\dagger) \\
( \pm 0.95)\end{array}$ \\
\hline$\Delta \operatorname{gadD1}$ & $\begin{array}{l}5.83 \\
( \pm 0.81)\end{array}$ & $\begin{array}{l}2.92 \quad(\dagger) \\
( \pm 0.02)\end{array}$ & $\begin{array}{l}3.93 \\
( \pm 0.34)\end{array}$ & $\begin{array}{l}2.86 \quad(\dagger) \\
( \pm 0.05)\end{array}$ & $\begin{array}{l}5.26 \\
( \pm 0.37)\end{array}$ & $\begin{array}{l}3.83 \quad(\dagger) \\
( \pm 0.14)\end{array}$ \\
\hline$\triangle \operatorname{gadD2}$ & $\begin{array}{l}6.77 \\
( \pm 1.09)\end{array}$ & $\begin{array}{l}3.01 \quad(\dagger) \\
( \pm 0.04)\end{array}$ & $\begin{array}{l}3.78 \\
( \pm 0.36)\end{array}$ & $\begin{array}{l}2.85 \quad(\dagger) \\
( \pm 0.01)\end{array}$ & $\begin{array}{l}6.22 \\
( \pm 0.45)\end{array}$ & $\begin{array}{l}3.66 \quad(\dagger) \\
( \pm 1.06)\end{array}$ \\
\hline$\Delta \operatorname{gadD3}$ & $\begin{array}{l}6.63 \quad(*) \\
( \pm 0.78)\end{array}$ & $\begin{array}{l}2.97 \quad(\dagger) \\
( \pm 0.002)\end{array}$ & $\begin{array}{l}5.26 \quad(*) \\
( \pm 0.23)\end{array}$ & $\begin{array}{l}3.09 \quad(\dagger) \\
( \pm 0.05)\end{array}$ & & \\
\hline $\begin{array}{c}\Delta l m o 0913 \\
\text { or } \\
\Delta l m r g \_02013\end{array}$ & $\begin{array}{l}6.59 \\
( \pm 0.82)\end{array}$ & $\begin{array}{l}2.90 \quad(\dagger) \\
( \pm 0.01)\end{array}$ & $\begin{array}{l}5.61 \\
( \pm 0.79)\end{array}$ & $\begin{array}{l}3.13 \quad(\dagger) \\
( \pm 0.07)\end{array}$ & & \\
\hline$\Delta \operatorname{gadD} 1 / D 2$ & & & & & $\begin{array}{l}5.99 \\
( \pm 0.64)\end{array}$ & $\begin{array}{l}4.19 \quad(\dagger) \\
( \pm 0.31)\end{array}$ \\
\hline
\end{tabular}

(*) denotes statistically significant difference relatively to the WT strain, under the same condition.

$(\dagger)$ denotes statistically significance between $(+)$ and $(-) \mathrm{H}_{2} \mathrm{O}_{2}$, in each strain. 
Table 3. Maximum optical density $(620 \mathrm{~nm})$ of L. monocytogenes strains grown in the presence (+) or absence (-) of $\mathrm{H}_{2} \mathrm{O}_{2}$.

\begin{tabular}{|c|c|c|c|c|c|c|}
\hline \multirow[t]{2}{*}{ Max growth } & \multicolumn{2}{|c|}{$10403 S$} & \multicolumn{2}{|c|}{ EGD-e } & \multicolumn{2}{|c|}{ LO28 } \\
\hline & $\mathrm{H}_{2} \mathrm{O}_{2}(+)$ & $\mathbf{H}_{2} \mathbf{O}_{2}(-)$ & $\mathrm{H}_{2} \mathrm{O}_{2}(+)$ & $\mathbf{H}_{2} \mathbf{O}_{2}(-)$ & $\mathrm{H}_{2} \mathrm{O}_{2}(+)$ & $\mathbf{H}_{2} \mathbf{O}_{2}(-)$ \\
\hline WT & $\begin{array}{c}0.625 \\
( \pm 0.045)\end{array}$ & $\begin{array}{c}0.676 \\
(0.057)\end{array}$ & $\begin{array}{c}0.680 \\
( \pm 0.015)\end{array}$ & $\begin{array}{c}0.705 \\
( \pm 0.013)\end{array}$ & $\begin{array}{c}0.563 \\
( \pm 0.068)\end{array}$ & $\begin{array}{l}0.723(\dagger) \\
( \pm 0.040)\end{array}$ \\
\hline$\Delta \operatorname{gadD1}$ & $\begin{array}{c}0.636 \\
( \pm 0.030)\end{array}$ & $\begin{array}{c}0.623 \\
( \pm 0.005)\end{array}$ & $\begin{array}{c}0.661 \\
( \pm 0.023)\end{array}$ & $\begin{array}{c}0.675 \\
( \pm 0.012)\end{array}$ & $\begin{array}{l}0.81(*) \\
( \pm 0.023)\end{array}$ & $\begin{array}{c}0.822 \\
( \pm 0.01)\end{array}$ \\
\hline$\triangle \operatorname{gadD} 2$ & $\begin{array}{c}0.691 \\
( \pm 0.075)\end{array}$ & $\begin{array}{c}0.621 \\
( \pm 0.025)\end{array}$ & $\begin{array}{c}0.652 \\
( \pm 0.018)\end{array}$ & $\begin{array}{c}0.661 \\
( \pm 0.008)\end{array}$ & $\begin{array}{c}0.588 \\
( \pm 0.040)\end{array}$ & $\begin{array}{l}0.737(\dagger) \\
( \pm 0.040)\end{array}$ \\
\hline$\Delta \operatorname{gadD3}$ & $\begin{array}{c}0.660 \\
( \pm 0.08)\end{array}$ & $\begin{array}{c}0.633 \\
( \pm 0.02)\end{array}$ & $\begin{array}{c}0.643 \\
( \pm 0.02)\end{array}$ & $\begin{array}{c}0.666 \\
( \pm 0.005)\end{array}$ & & \\
\hline $\begin{array}{c}\Delta l m o 0913 \\
\text { or } \\
\text { slmrg_02013 }\end{array}$ & $\begin{array}{c}0.642 \\
( \pm 0.040)\end{array}$ & $\begin{array}{c}0.600 \\
( \pm 0.024)\end{array}$ & $\begin{array}{c}0.711 \\
( \pm 0.005)\end{array}$ & $\begin{array}{c}0.702 \\
( \pm 0.02)\end{array}$ & & \\
\hline$\Delta \operatorname{gadD1} / \mathrm{D2}$ & & & & & $\begin{array}{c}0.797(*) \\
( \pm 0.01)\end{array}$ & $\begin{array}{c}0.797 \\
( \pm 0.003)\end{array}$ \\
\hline
\end{tabular}

(*) denotes statistically significant difference relatively to the WT strain, under the same condition.

$(\dagger)$ denotes statistically significance between $(+)$ and $(-) \mathrm{H}_{2} \mathrm{O}_{2}$, in each strain. 
Fig. 1

A

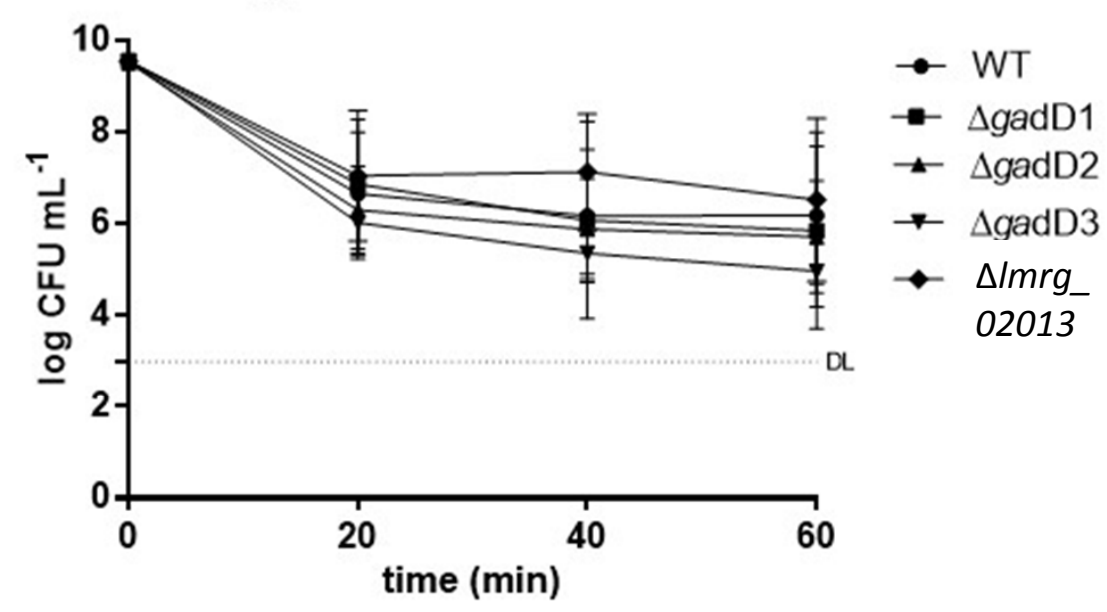

B

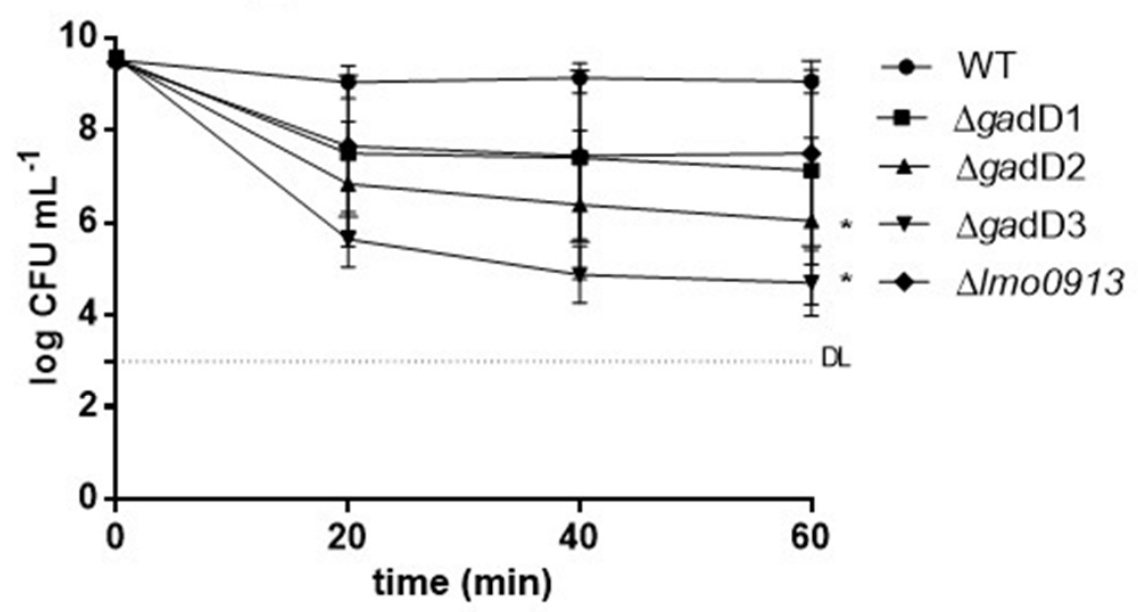

C

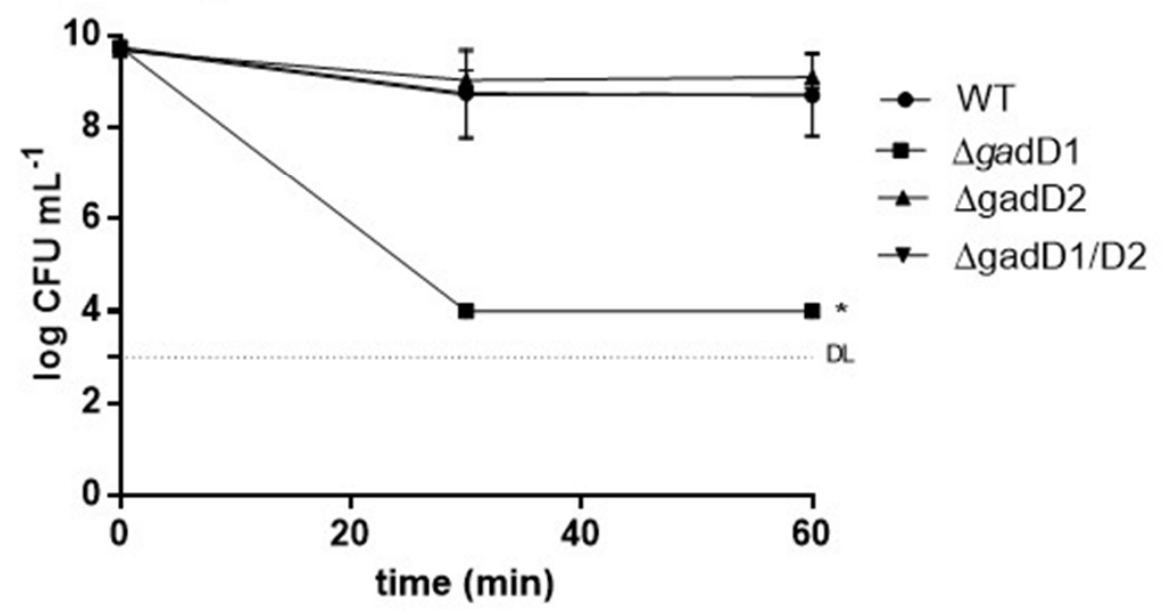


Fig. 2

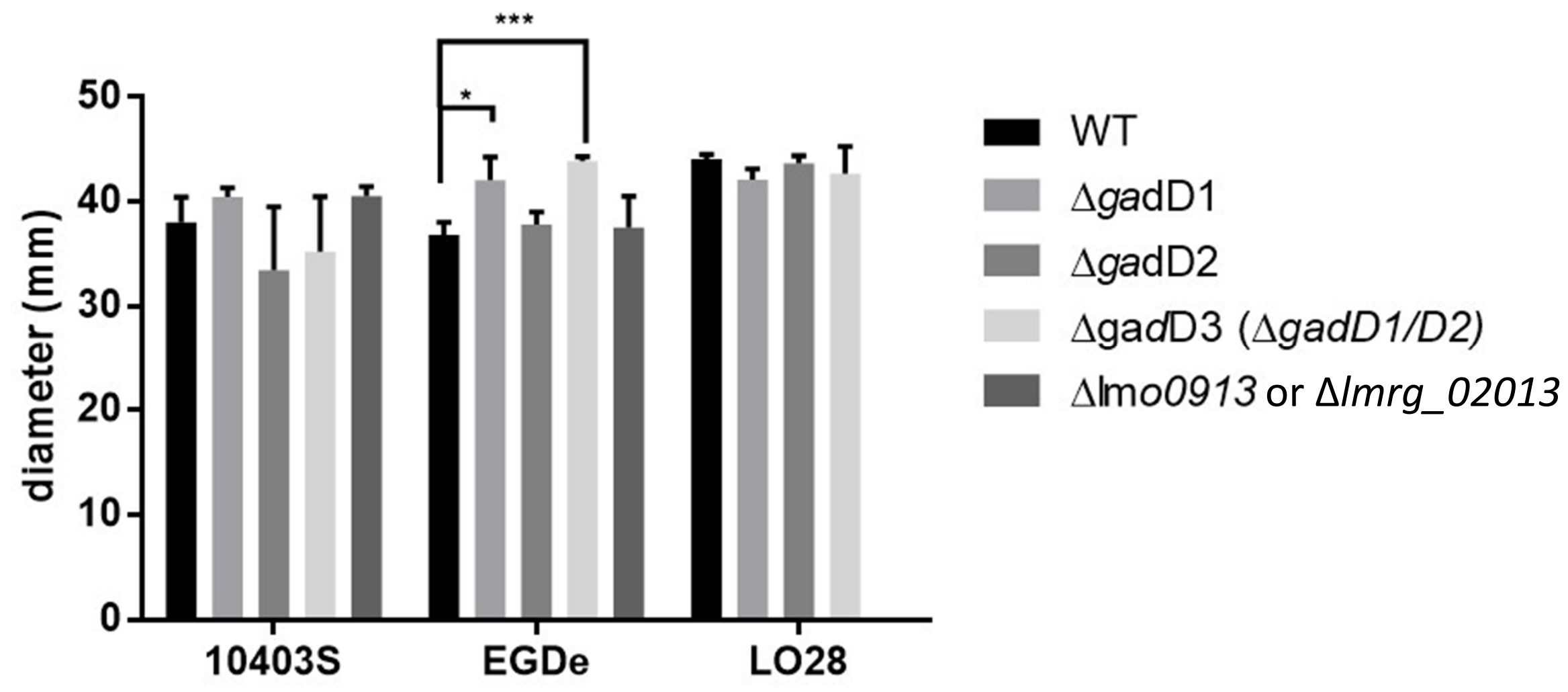


Fig. 3

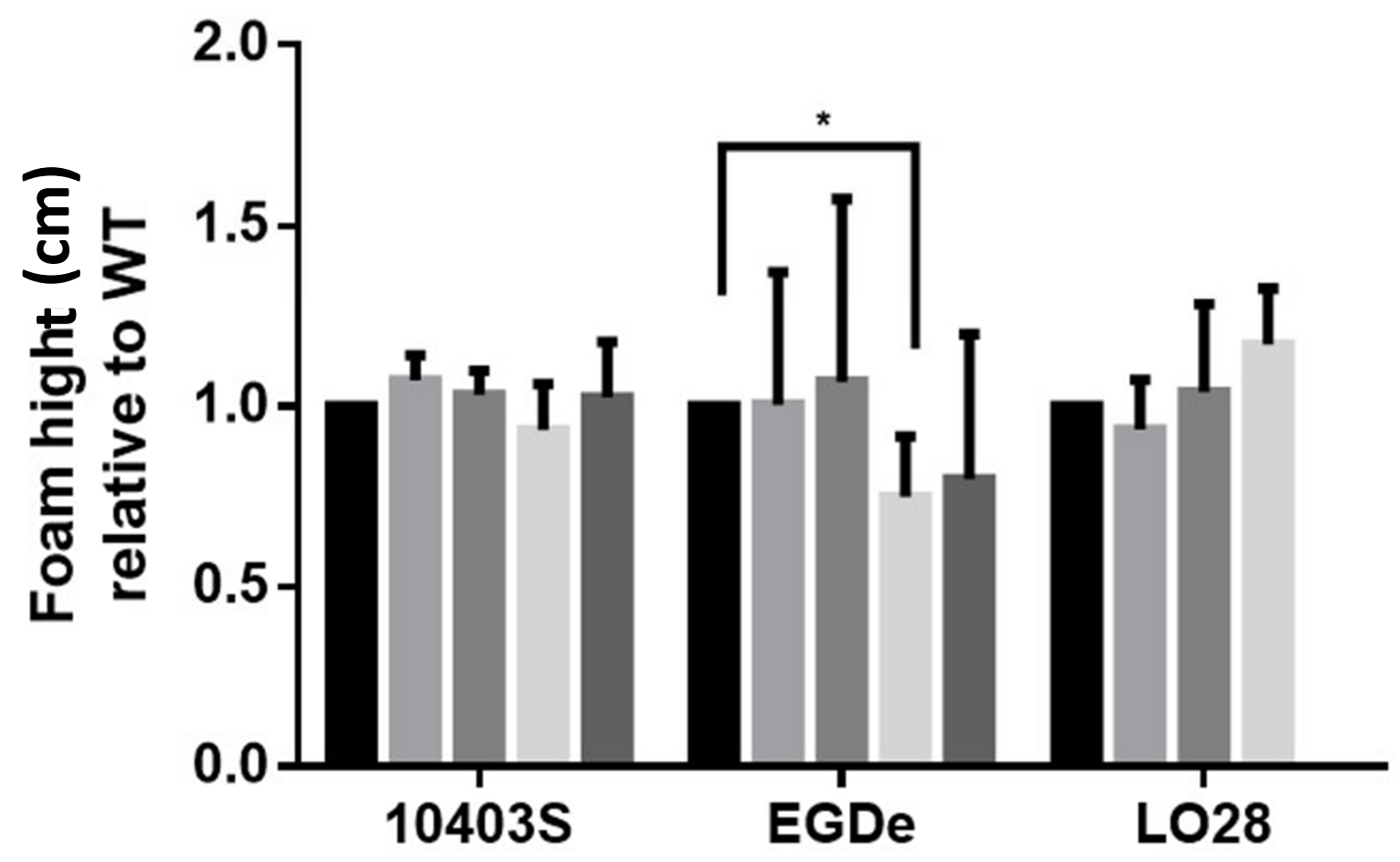

WT

$\Delta$ gadD1 $\Delta$ gadD2 $\Delta$ gadD3 ( $\Delta$ gadD1/D2) $\Delta / m o 0913$ or $\Delta / m r g \_02013$ 
Fig4
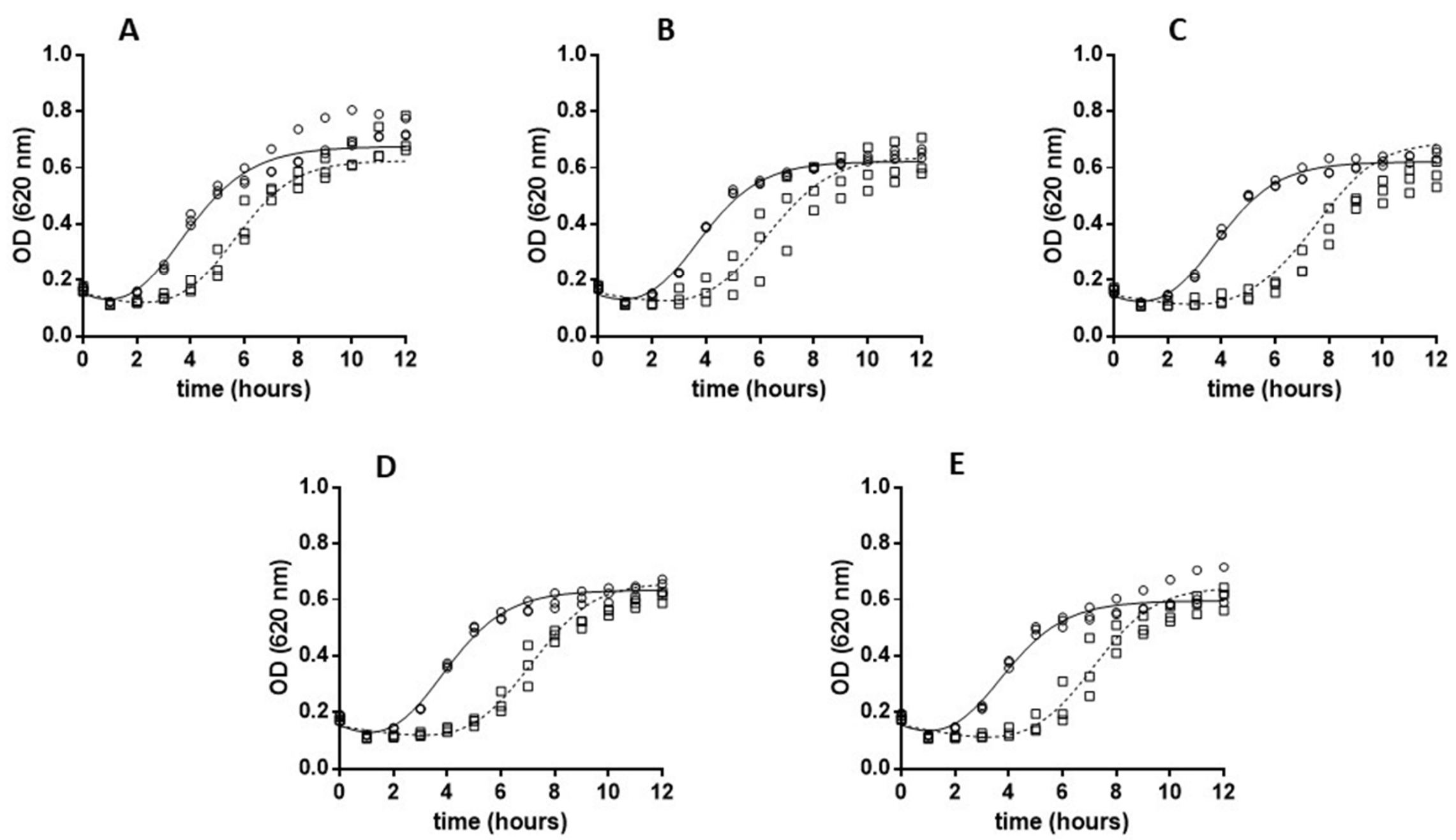
Fig5
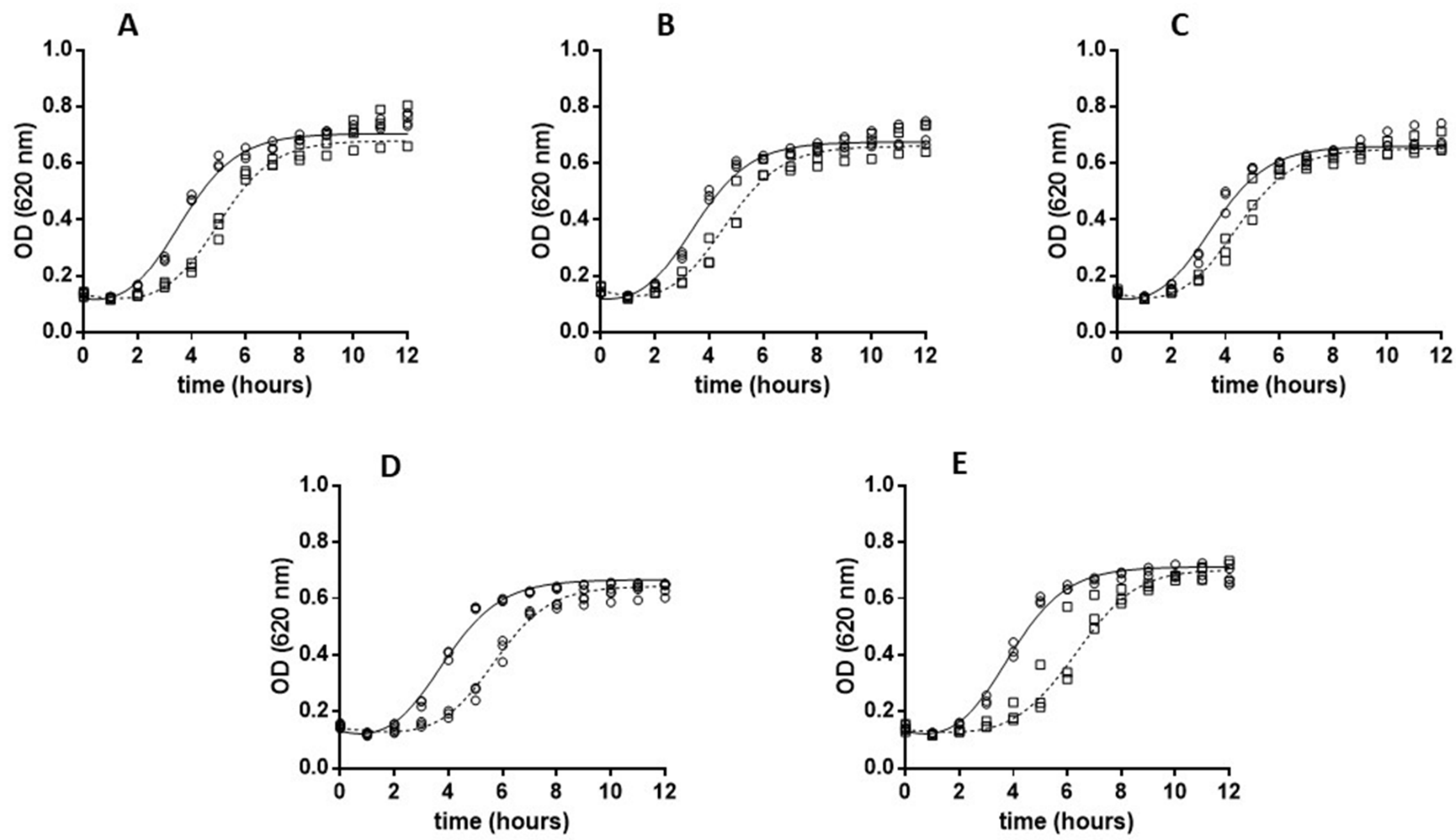

EGD-e 
Fig. 6
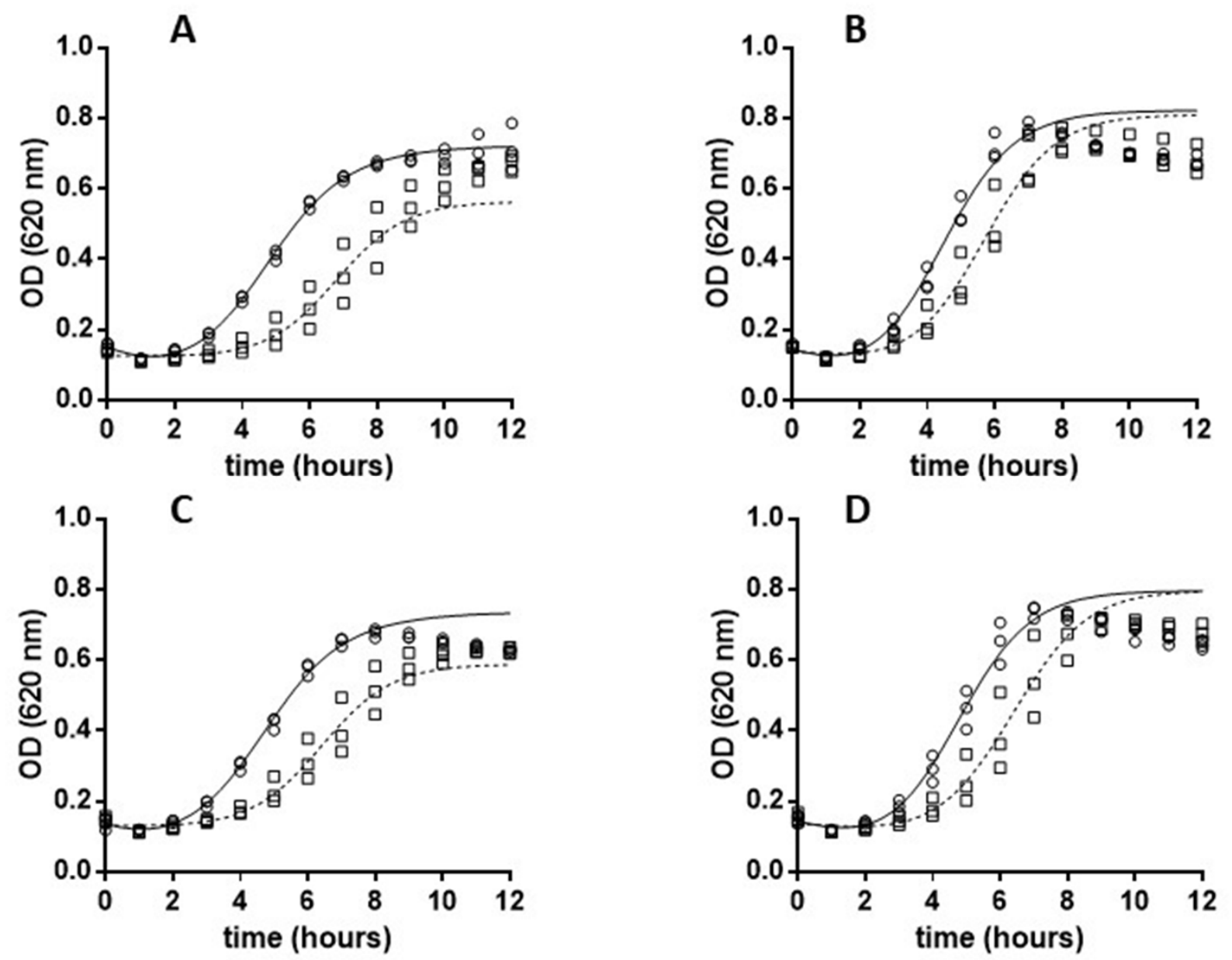
Fig.7

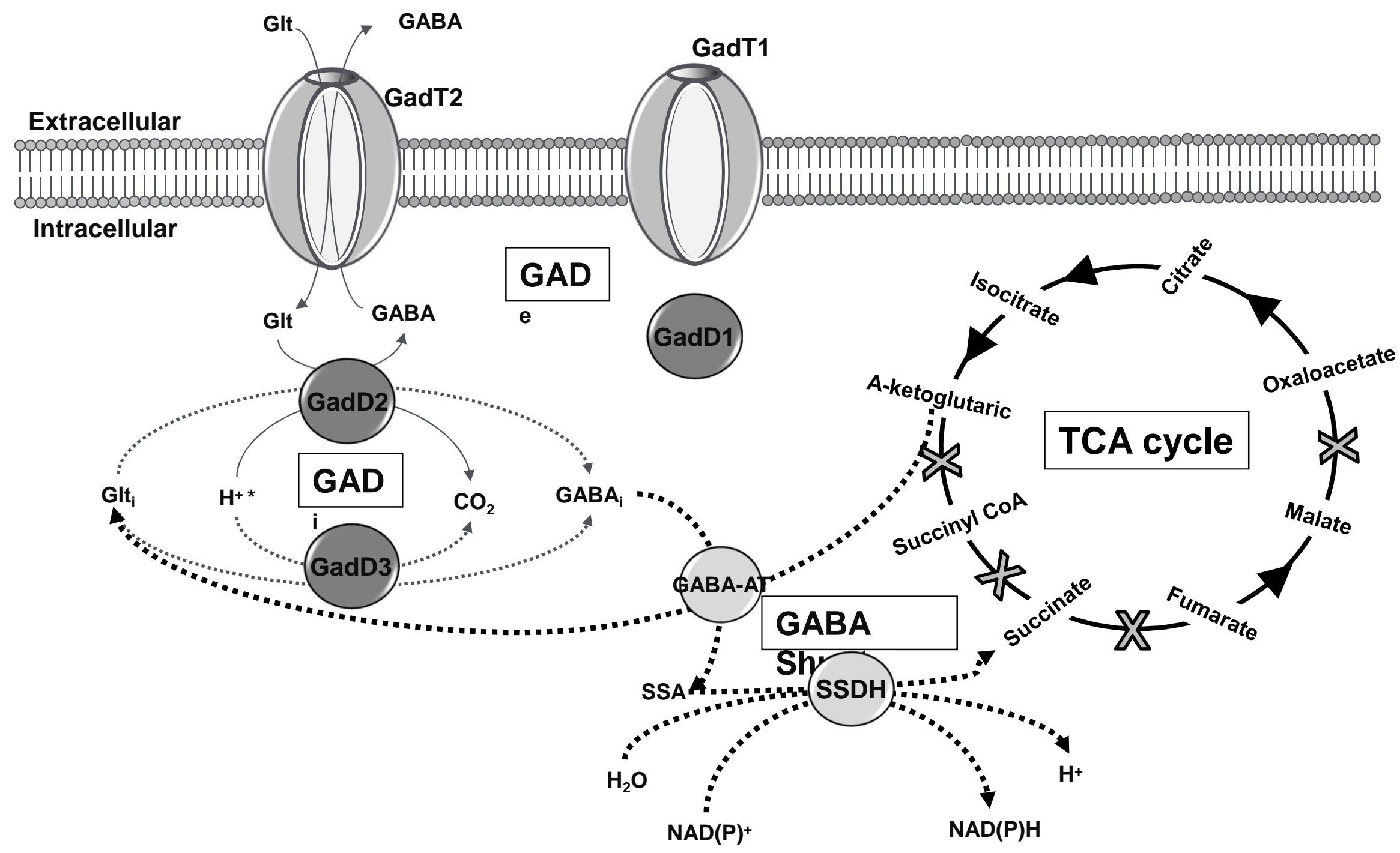




\section{Highlights}

- The GAD system affects oxidative stress resistance in a Gram-positive bacterium $(L$. monocytogenes)

- The $\mathrm{GAD}_{\mathrm{i}}$ and mainly GadD3 affects oxidative stress resistance in L. monocytogenes

- The $\mathrm{GAD}_{\mathrm{e}}$ system does not affect oxidative stress resistance in L. monocytogenes

- GadD1in LO28 has a novel role in oxidative stress resistance

- SSDH of GABA shunt does not affect oxidative stress in L. monocytogenes. 
Declarations of interest: none 